\title{
ÉTICA E AIDS NO LOCAL DE TRABALHO: A CONTRIBUIÇÃO DO PROFISSIONAL ENFERMEIRO
}

[Ethics and AIDS in workplace: the contribution of the nurse]

Carolina Bocchi Maia*

Maria de Lourdes Centa**

RESUMO: O objetivo deste ensaio é o de proporcionar uma reflexão referente às questões éticas a partir do crescente aumento nos casos de AIDS ocorrendo junto à população economicamente ativa, destacando o papel do enfermeiro do trabalho integrante de equipes de saúde ocupacional e sua importante contribuição no implemento das estratégias de prevenção para enfrentamento desta epidemia que afeta a humanidade de maneira perversa.

PALAVRAS CHAVE: Ética de enfermagem; local de trabalho; AIDS.

\section{INTRODUÇÃO}

As discussões em torno do termo ética são muito freqüentes e autores demonstram uma preocupação, conquanto parece não haver consonância sobre a sua conceituação. Independentemente de uma acepção mais aprofundada a respeito da ética, acredito que esta deve ser situada como uma preocupação pela realização das pessoas a partir de suas potencialidades originárias.

Explanações nesta seara se fazem relevantes, principalmente quando lançamos um olhar para o campo da AIDS, terreno fértil e extremamente complexo, que traz à baila questões

"Enfermeira, Especialista em Enfermagem do Trabalho, Professora da Disciplina de Ética e Legislação em Enfermagem da Faculdade Evangélica do Paraná, Mestranda em Enfermagem na Universidade Federal do Paraná.

**Enfermeira, Doutora em Filosofia de Enfermagem, Professora Sênior do Curso de Mestrado em Enfermagem da Universidade Federal do Paraná. de cunho ético requerendo de todos considerações sobre o comportamento e atitudes frente à epidemia, e principalmente no que se refere ao papel dos profissionais de saúde, incluindo em especial, os enfermeiros.

Ao longo de duas décadas a humanidade vem convivendo com a epidemia da AIDS, que a despeito dos inúmeros recursos que já foram mobilizados para contê-la, ainda se depara com atitudes arbitrárias, perversas e discriminatórias em função do estigma social que a doença suscita, gerando desigualdades sociais e conflitos subjetivos originários do preconceito, culpa e exclusão e que levam as pessoas abaladas por ela a sofrerem situações de extrema fragilidade e sofrimento emocional. O desafio, portanto, permanece presente e exige esforço de todos e de cada um, como contrapartida, para o enfrentamento deste problema que afeta a humanidade de maneira indistinta.

Como enfermeira do trabalho, durante 16 anos desenvolvendo atividades de educação em saúde em diversas empresas, venho por meio deste ensaio propor uma reflexão sobre as questões éticas que permeiam o conviver com o HIV e a AIDS no âmbito dos locais de trabalho, ressaltando a importância da atuação do enfermeiro na equipe de saúde ocupacional.

\section{QUESTÕES ÉTICASE A OCORRÊNCIADA AIDS}

Gelain (1998) descreve que a palavra ética, de origem grega, refere-se aos comportamentos que caracterizam uma cultura, a compreensão da tradição e as experiências comuns de um profissional baseados numa hierarquia de valores; é o modo de ser, os hábitos, o caráter. Para os 
gregos, o "ethos", anteriormente mencionado, constituía uma segunda natureza no homem, a partir da qual podia reconhecer duas formas de um modo próprio do seu existir considerando que a ética é uma característica do ser humano, delimitada em diversas dimensões, tendo em vista a sua atuação.

O mesmo autor considera existir diferentes modelos éticos que introduzem uma direção éticofilosófica, quais sejam: o tradicional, o legitimador, o renovado, o idealizante, o social, o problematizador e o estético, e que apesar de suas diferenças, deixa claro que não se admite mais a visão apenas normativa, legalista e tão pouco à preocupação personalista isolada, em que pese à necessidade de respeitar a individualidade do cliente, mas se faz necessário ampliá-lo para o contexto social onde se encontra inserido.

Posteriormente, surge em Roma, o termo moral, entendido como normatização dos atos humanos práticos, dos costumes, dos deveres do homem individual e grupal (VASQUEZ, 1999).

Os termos ética e moral, mesmo conciliando semanticamente, ao serem introduzidos no mundo europeu acabaram recebendo, segundo Fontinele (2000), no processo de desenvolvimento cultural, significados diversos, no qual comportamento moral referia-se a questão de ordem prática, o que fazer em cada situação prática, enquanto ética compreendia reflexão sobre esse comportamento prático.

No que se refere a deontologia, a sua ênfase reside no estudo dos deveres de um grupo profissional tendo por base os valores aceitos, mas formando um conjunto de outras disciplinas e não existindo isoladamente (GELAIN, 1998).

A partir de 1970, a bioética aparece no horizonte científico, como o estudo interdisciplinar dos problemas criados pelo progresso biomédico, sua repercussão na sociedade e seu sistema de valores. Possui identidade instável e situa-se na confluência do saber tecnocientífico, especialmente biológico, com as ciências humanas, como a sociologia, a política, a ética e a teologia (PESSINI e BARCHIFONTAINE, 2002). Visto de outra maneira, segundo a Encyclopedia of Bioethics, bioética é o estudo sistemático das dimensões morais, incluindo visão e conduta humana nas áreas das ciências da vida e dos cuidados da saúde, na medida em que esta é examinada à luz dos valores utilizando-se de uma variedade de metodologias éticas num contexto multi, inter e transdisciplinar. Segundo alguns autores, ela abrange principalmente aspectos relacionados com o começo da vida e com a qualidade da morte e baseia-se em princípios incluindo a autonomia, a não maleficência, a beneficência e a justiça (PARANÁ, 1997; GELAIN, 1998). Estes princípios facilitam e ordenam a análise de casos concretos e, a partir de então, permitem que seja aprofundada a análise ética, na relação dos profissionais de saúde e seus clientes.

Em suma, o que se busca por meio da bioética, é desenvolver uma responsabilidade conscientizadora para a conquista dos direitos e valores de cidadania, do ponto de vista ético e biológico e realizado de forma ecumênica e dinâmica, numa perspectiva dialogal e pluralista, haja vista a complexidade objetiva das questões que se levantam. Independentemente da cultura, raça, credo, ideologia e condição social, a bioética configura-se, portanto, como uma nova sensibilidade humana, comum a todos aqueles que anseiam pela necessidade de defender e promover a vida no sentido mais amplo, por meio do estudo dos avanços da ciência em função da pessoa (PESSINI e BARCHIFONTAINE, 2002).

Da mesma forma, observa-se que na história da ética, o conceito de pessoa também sempre ocupou um lugar de destaque. A idéia inicial, vigente até o século XIX, centrava-se na sua essência, dotando-a simplesmente de racionalidade. A partir de então, houve uma ampliação do conceito de pessoa observado pela introdução da historicidade e temporalidade na existência humana, alterando o que se acreditava verdadeiro sobre a essência, definida e consolidada desde o momento da concepção, e manifestada pela expressão "ser o que sempre foi". Atualmente o conceito mais utilizado considera a pessoa como uma existência temporal, relacional e potencial, que se constrói ao longo da vida, a partir das relações que estabelece consigo, com os outros, com Deus e com o mundo, demonstrando suas potencialidades (PEGORARO, 2002).

Partindo deste raciocínio, o mesmo autor reitera ser muito difícil, defender uma teoria ética que parta de princípios fixos e válidos para todos os seres humanos em todos os tempos, uma vez 
que a ética é flexível e se adapta a situação real da vida. Em cada situação, acrescenta, há que se inventar, descobrir e criar o caminho cujo horizonte ético abarque justiça, solidariedade e paz. Cada época, portanto, tem seu próprio modo de desenvolver solidariedade, de fazer justiça e de promover a paz, bem como, não se restringe ao agir humano, mas exige pensar em outras formas de vida, animal e vegetal, na qual cada uma possui a sua própria qualidade ética.

Neste sentido, surge o que se denomina a ética da solidariedade antropocósmica, que segundo Pegoraro (2002), é aquela que estabelece a reconciliação entre a ciência e a ética, superando as mútuas desconfianças e rejeições existentes na definição do horizonte do saber, elucidando uma para a outra, em caráter complementar, o saber tecnocientífico e o saber simbólico da filosofia e da ética, de tal forma que exista a convivência e o progresso da vida sobre a terra.

Refletindo sobre as questões supracitadas de Pegoraro (2002), penso na epidemia do HIV e da AIDS como fenômeno hodierno de grande magnitude e extensão que afeta vidas do planeta como um todo, presente em nosso meio há pouco mais de 20 anos e que trouxe questões extremamente complexas não somente de ordem médica, mas sociais, econômicas, políticas, culturais e éticas. Ela surgiu numa época na qual assistimos a celebração de corpos extremamente saudáveis, harmoniosos e quase imortais graças aos diversos aparatos das novas tecnologias e das ciências biomédicas; além da busca pelo exercício de uma sexualidade democrática nas suas diversas possibilidades de manifestações. Foi então, no âmbito da sexualidade e na queda do mito da imortalidade, que a AIDS ancorou sua grande e controversa discussão com ênfase para os aspectos inerentes à ética e moral.

A forma como ela surgiu fez o mundo experimentar o recrudescimento de posturas obscurantistas e discriminatórias contra alguns grupos sociais denominados de "risco" e que foram e têm sido identificados como os mais suscetíveis à aquisição da doença, representados pelos homossexuais masculinos, usuários de drogas injetáveis, profissionais do sexo e hemofílicos (SILVA, 1995).

Questiono esta ideologia, pois sendo o HIV e a AIDS uma doença sexualmente transmissível e, como tal, presente em grupos humanos que têm em comum o fato de se relacionarem sexualmente, como ela poderia ficar circunscrita a grupos específicos? Concordo com SILVA (1995) quando diz que na verdade o que tais posturas pretendiam, era ratificar a intolerância em face de comportamentos considerados indesejáveis e transgressores da moral vigente. Estes comportamentos ditos indesejáveis incluem práticas alternativas, principalmente em relação ao exercício da sexualidade, que diferem e contrariam o código moral interno existente, considerado como imperativo de conduta eticamente aceitável pela maioria das pessoas. Contudo o seu trilhar nos revelou uma verdade incômoda, na qual homens, mulheres e gradualmente, crianças, independente de religião, raça, idade, sexualidade ou situação socioeconômica, encontraram-se também vulneráveis a infecção provocada pelo HIV e pela AIDS, sobretudo nos segmentos que estão em situação de maior desigualdade e opressão social.

A AIDS é uma epidemia marcada por uma história que evidencia a exclusão social no Brasil e no mundo, suscitando várias questões de natureza ética e científica. O seu mapa epidemiológico seguiu não só um perfil biológico do desenvolvimento da epidemia, mas principalmente um perfil social de vulnerabilidade dos diversos segmentos da população. Esta vulnerabilidade tanto diz respeito ao nível individual quanto ao coletivo e pressupõe um conjunto de fatores e magnitude distintos, cuja interação aumenta ou reduz as possibilidades de uma pessoa se infectar pelo HIV (BRASIL, 1999).

Entendida também como possível doença que se cronifica, ela apresenta peculiaridades que a torna muito complexa, pois apesar dos avanços tecnológicos obtidos, sobretudo na área de atenção à saúde, em função da distribuição universal dos medicamentos antiretrovirais, ocorrida no Brasil a partir de 1996 e a conseqüente melhoria da qualidade de vida dos sujeitos, a ciência ainda enfrenta diversas dificuldades para contê-la. Tal questão se dá pela inexistência de vacinas e o fato da transmissão do HIV ocorrer principalmente por meio das secreções sexuais, do sangue e leite contaminados, cuja prevenção baseada inteiramente na capacidade de interrompê-la, 
depende de profundas mudanças nas práticas sexuais e comportamentais, em especial no que se refere à sexualidade (VILLELA e DINIZ, 1998).

Por muito tempo, falou-se mais do "doente" do que da "doença", com ênfase para o fato de a epidemia ser restrita aos grupos de risco. Esta idéia reforçou o preconceito e a crença de que as pessoas heterossexuais não tinham relação com a epidemia e que, portanto, não precisavam adotar posturas concretas para o seu enfrentamento, na medida em que se julgavam imunes à mesma (ZAMPIERI, 1996).

A referida autora menciona que enquanto a AIDS biológica avançava de maneira silenciosa, esta outra, denominada de AIDS imaginária negava as particularidades de realidade infecciosa no segmento de pessoas com práticas heterossexuais, indicando que esta síndrome, não escapou a regra geral de outras doenças, segundo a qual o ser humano tende a subestimar os riscos comuns e a sobrestimar os de conseqüências catastróficas, porém, que permanecem invisíveis, distantes e abstratos.

Importante salientar que doença e doente são fatos sociais codificados culturalmente. Dessa forma as doenças podem sofrer interpretações ou explorações moralistas, que, no caso da AIDS, se dão sob a forma de condenações individuais a certos grupos, separando os culpados e as vítimas da doença, do restante da população, favorecendo a crença de que só os "outros", aqueles com prática de comportamentos considerados desviantes, podem contraí-la. ZAMPIERI (1996) pondera que a categoria "outro" é inadequada, haja vista que gera uma invisibilidade que obscurece a informação, tornando suscetíveis à infecção pelo HIV, aqueles que não conseguem ou não querem pensar que a AIDS é possível para suas vidas. Neste sentido, é importante considerar o quanto se torna mais fácil e confortável negar a possibilidade de se ver vulnerável, ao invés de enfrentá-la.

Apesar de comprovadas cientificamente somente três categorias de transmissão até o presente momento, sendo a sexual, a sangüínea e a perinatal, a humanidade num misto de incredulidade, pasmo e medo, mesclada com atitudes discriminatórias, continua denunciando os mais variados preconceitos de forma intensa e acende inclusive, reações de pânico desproporcionais ao grau de transmissibilidade atribuída ao HIV, demonstrada pelas pesquisas epidemiológicas, sinalizando que a construção imaginária em relação a AIDS, muitas vezes, prevalece sobre a verdade científica.

Segundo PAIVA (1992), o abismo existente entre o risco objetivo de contrair o HIV e o risco tal como é percebido individualmente ou por grupos, alimenta medos, boatos e controvérsias que pesam e dificultam as formas práticas de gestão do risco e, por conseguinte, as estratégias de prevenção. Além disso, o portador ou doente de AIDS não traduz uma identidade coletiva com necessidades iguais. O que compartilha em comum é o estigma que a construção social da doença produziu. O estigma, considerado como um atributo que é profundamente depreciativo, é visto pela sociedade como relacionado a alguém que possui uma diferença indesejável e incongruente com o estereótipo que criamos para um determinado tipo de indivíduo e que, portanto, apresenta uma identidade deteriorada (GOFFMAN, 1988).

Entendido desta forma, o estigma é mapeado sobre as pessoas, que se aceitam como negativamente valoradas na sociedade. Entretanto, este conceito de estigma é um fenômeno histórico, social e cultural ligado às ações de grupos de pessoas e não conseqüência de comportamentos individuais.

A AIDS lembra que é humano ter medo do que é posto fora dos padrões e dos códigos compartilhados pela maioria das pessoas, ou seja, temer aquilo que está além das suas fronteiras. Lá está o inexplorado, o sombrio e, assim sendo, o senso comum apresenta razões lógicas para permanecer adaptado ao que todo mundo acha certo ou faz. Trabalhar preconceitos, medos e respeito à diferença é indispensável, na tentativa de buscar uma aproximação com o outro lado, sendo capaz de percebê-lo como ponte de nós mesmos. É compreender a universalidade do ser humano, sem desconsiderar sua especificidade (PAIVA, 1992).

\section{AIDS E O LOCAL DE TRABALHO}

A partir do recrudescimento da incidência da AIDS estendendo-se de forma intensa aos ambientes de trabalho, certos itens, antes pouco 
valorizados, mereceram uma profunda reflexão, sobretudo em relação ao desenvolvimento de uma consciência ética profissional. Esta compreensão reconhece no outro - ainda que ele seja diferente a nossa própria humanidade, por meio de uma convivência democrática pautada pelos direitos universais humanos e de cidadania. A falta deste tipo de consciência significa, do ponto de vista ético, considerar umas pessoas, no caso as soronegativas, mais cidadãs do que as soropositivas, passando, portanto, a condição de cidadã para o segundo plano em relação ao seu status sorológico para o HIV (BRASIL, 2001).

Ressalte-se que atualmente no Brasil, a faixa etária compreendida entre 20 e 49 anos e também considerada como no auge da vida produtiva, sexual e reprodutiva, é a mais atingida pela AIDS, fato que justifica a necessidade de atuação conjunta e articulada de muitas áreas do conhecimento para dar cabo às diferentes demandas.

Neste sentido, os locais de trabalho ostentam características que os tornam ambientes propícios ao desenvolvimento de estratégias de prevenção que promovam mudanças de atitudes frente à epidemia provocada pelo HIV. Nele, as pessoas passam a maior parte de suas vidas e desenvolvem relações de afeto e cumplicidade que, muitas vezes, subvertem a mais elementar ordem hierárquica. É também neste cenário, com grande capacidade de mobilização que as ações de educação preventiva devem ser intensificadas, adequando-as às particularidades dos trabalhadores, haja vista que estes tendem a confiar muito, quando as informações procedem da própria empresa (MAIA, 2003).

A Organização Internacional do Trabalho (OIT) na Declaração de Consenso sobre AIDS referiu que "a infecção por si só não significa limitação para o trabalho, além de que a "confirmação sorológica não configura motivo para demissão" assegurando o que é estabelecido pelo princípio da confidencialidade, direito de todo cidadão, o qual tem como objetivo evitar danos que certamente estariam presentes a partir da revelação de resultado positivo para HIV de um trabalhador. Igualmente, não há justificativa técnica, ética, legal ou social que possibilite aos empregadores exigir tais testes, especialmente quando estes ocorrem sem o conhecimento e consentimento prévios dos sujeitos.

Contudo, o que se verificou na prática foi justamente o contrário. As empresas preocupadas com a disseminação do HIV junto aos trabalhadores passaram a exigir que os profissionais de saúde ocupacional solicitassem de forma compulsória os testes sorológicos anti-HIV nos exames admissionais e periódicos, demitindo, muitas vezes, aqueles que apresentassem resultado positivo, criando em decorrência, conflitos com a conduta eticamente aceitável nestas circunstâncias (PARANÁ, 2003). Este fato suscitou discussão de várias questões de natureza ética, causando uma série de modificações tanto nas investigações quanto nas intervenções e enlaçando de formas diferentes, porém inseparáveis, uma dimensão cognitiva e uma moral na busca de atitudes mais adequadas dos profissionais de saúde envolvidos no processo de atenção à vida dos trabalhadores afetados.

A postura arbitrária evidenciada por parcela do empresariado, oportunizou aos profissionais de saúde ocupacional, incluindo os enfermeiros, de um lado, a reflexão sobre sua vida pessoal e vulnerabilidade ao HIV, ao mesmo tempo em que evidenciou neste segmento, o forte preconceito e conseqüente discriminação em relação a sua dificuldade de lidar com aspectos relacionados à sexualidade e a morte, dentro dos ambientes de trabalho. Afinal, a sexualidade humana é muito diversa e complexa daquilo que é normalizado, falado e até pensado. A AIDS veio precipitar um descortinar para esse mundo sexual, oculto e desconhecido, porém presente na vida das pessoas de maneira inequívoca e indissociada, apesar do desejo consciente ou inconsciente de ocultá-lo.

Muitos profissionais de saúde ocupacional foram contaminados pelo exagerado medo da AIDS e temas afins, recusando-se a prestar atendimento aflorando com isso, questões relacionadas ao desrespeito e abandono do cliente, quebra de sigilo profissional, dificuldades na relação médica paciente, entre outros. Estas situações, presentes de forma cotidiana em diversos ambientes de atuação profissional, motivaram o Conselho Regional de Medicina de São Paulo a redigir, em 1988, a Resolução intitulada "AIDS e Ética Médica" e que posteriormente, serviu de base para os demais Conselhos Profissionais de Saúde no 
Brasil, na elaboração de suas regulamentações éticas.

Decorridos alguns anos a partir da publicação desta Resolução e apesar dos avanços na tentativa de transformar a fundamentação nela contida em ação ética, ainda permanecem presentes alguns impasses. Não obstante às evidências que apontam para a eficácia das medidas de biossegurança no exercício do trabalho, como barreira impeditiva à transmissão do HIV, existem posicionamentos de ordem moral observados na prática, que têm gerado sofrimento e desgaste desnecessários aos trabalhadores soropositivos para o HIV.

Inicialmente, tudo o que se refere à doença e à morte se exprime por meio das preocupações ligadas ao contágio, a manifestação da doença propriamente dita, ao sofrimento físico e psicológico, à deterioração e à dependência física e emocional. De fato esta dimensão se organiza em torno do processo de morte do outro, daquilo que é certo, porém desconhecido e nunca antes vivenciado, e por associação, expressa ao redor da possibilidade da morte do cuidador como indivíduo. O impacto sobre o real e o imaginário de ambos, cuidadores e pessoas que são cuidadas, no que tange a carga emotiva que eles têm que assumir, apesar de possuírem intensidades diferentes acabam interferindo e, por vezes, imobilizando-os para ação (BRASIL, 2000).

Dentro da empresa, a área de saúde ocupacional, muitas vezes, ocupa um lugar estratégico na esfera de formulação das políticas internas, voltadas a vida dos trabalhadores. Se estrutura como um campo particular de saber, onde segundo Leopardi (1999), possui características próprias, interligando-se estreitamente com as concepções sobre a vida e morte, especialmente na forma de organização do seu processo de trabalho. Dentre as suas atribuições, a área de saúde ocupacional é responsável pela prestação de atendimento às necessidades dos trabalhadores que buscam ajuda para prevenir, manter, recuperar e ampliar suas capacidades vitais bio-subjetivas, simbólicas e relacionais, decorrentes de problemas originados dentro e fora do ambiente de trabalho, interferindo, desta forma, no processo saúdedoença, no contexto no qual se encontra inserido.

$\mathrm{O}$ enfermeiro do trabalho integrante desta equipe assume um papel relevante, não apenas pela sua formação técnica, mas, sobretudo, pela capacidade de ver e compreender o trabalhador na sua plenitude, podendo atendê-lo nas suas particularidades. Tal situação se faz possível, quando se cria no local de trabalho, uma atmosfera acolhedora, propícia para o estabelecimento, em conjunto com o trabalhador, de estratégias alternativas para sua vida, distantes do HIV, onde se consiga extrair algo intrínseco, que já existe. Entendida desta forma, cito Boff (1999) quando expressa que a educação age como um processo que acontece na pessoa, pela pessoa, com o auxílio de uma outra pessoa, estabelecendo-se uma relação de "com-vivência" de "inter-ação".

Além disso, pautada na expressão relacional e afetiva "educare" que segundo Geib e Saupe (2000), significa aglutinação do educar e do cuidar como possibilidade de cisão entre estas duas funções e que transcende a preocupação com a mudança de comportamento, o enfermeiro do trabalho pode demonstrar também, sua enorme contribuição na desmistificação da AIDS como algo circunscrito a grupos específicos, mas ao contrário, como um problema que afeta a humanidade, com ênfase para a população economicamente ativa.

Neste sentido, e considerando a complexidade de fatores que envolvem a AIDS, questionei-me durante os vários anos de atuação como enfermeira do trabalho integrante de equipes de saúde ocupacional, sobre qual era a conduta que poderia adotar no sentido de colaborar efetivamente com os trabalhadores no planejamento da sua vida a partir da revelação da sua soropositividade para o HIV ou nas ações de educação em saúde de forma mais ampla, com vistas à aquisição de hábitos seguros com relação à redução de risco para a infecção pelo vírus. Baseado em meus conhecimentos, aliada a prática profissional, pautada por sensibilidade e criatividade como enfermeira do trabalho, as ações foram traçadas em parceria com os trabalhadores, os quais acabaram por refletir um conjunto de estratégias para a prevenção incluindo: a definição de prioridades e conseqüente assunção das responsabilidades; discussão de temas relacionados ao estigma, preconceito e discriminação; mecanismos de transmissão e formas de prevenção; a importância dos testes anti- 
HIV; adesão medicamentosa e complementar; aconselhamento sexual, reprodutivo e de amamentação; aspectos legais e trabalhistas; uso de drogas; questões emocionais e morte.

Empreender estas atividades sob o ponto de vista ético, não foi tarefa fácil, pois naquela época, as fontes que pudessem oferecer subsídios para respaldar a minha atuação profissional em relação às especificidades da AIDS, eram escassas. De igual sorte, as naturezas das demandas eram tão diversas que exigiram muito estudo e análises crítico-reflexivas, em relação aos meus próprios valores, conceitos e preconceitos, para poder atuar como elemento facilitador e de apoio para os sujeitos que se encontravam em diferentes estágios de envolvimento e comprometimento com questões referentes à sua saúde.

Frente um fenômeno desafiador de ordem mundial, que se apresenta de forma extremamente diverso e volátil, que não tem fronteiras geográficas e afeta todo o mundo, faz-se necessário um esforço coletivo seja no âmbito internacional, nacional, estadual, municipal e empresarial para 0 enfrentamento e superação do mesmo. Para tanto, reafirmo com o estabelecido por Mann, Tarantola e Netter (1993) que é preciso refletir no global e agir no local, como sugerem os ecologistas. Refletir no global significa reconhecer que o trabalho contra a AIDS tem a capacidade de transcender o horizonte imediato, enquanto que agir no local pode significar agir em mim mesmo, tornando-me um agente na luta contra esta epidemia, atuando naquilo que está a minha frente, mais próximo, uma vez que o conhecimento, o compromisso e a ação em nível individual podem realmente fazer diferença.

A revolução provocada pela AIDS também obriga aos profissionais, incluindo os enfermeiros, repensar as características de sua constituição social de um modo muito mais premente, criando alternativas imprescindíveis que incidam sobre as barreiras já instaladas de preconceito e discriminação, que obtenham o efeito desejado para controlar a epidemia, enquanto aguardamos a sua cura (VALLE, 1997).

\section{CONSIDERAÇÕES FINAIS}

A compreensão da enorme variedade de fatores que presidem, no plano existencial, afetivo, social e ético, as relações entre cada indivíduo e o mundo que o cerca, podem proporcionar uma situação favorável ao encaminhamento adequado das alternativas de abordagem dos problemas que surgem em função da AIDS.

A partir do amplo espectro de cientistas e instituições, nacionais e internacionais, que disputam o espaço na construção do conhecimento a seu respeito, é possível dizer que o produto desta complexa interação marca indelevelmente a AIDS como uma epidemia permeada pela necessidade de atuação interdisciplinar, pela transitoriedade acerca das certezas e verdades sobre a doença e suas conseqüências, pela dificuldade de adoção de medidas eficazes de prevenção, bem como pelas respostas oferecidas ao seu enfrentamento. Neste contexto, os enfermeiros do trabalho como partícipes desta rede de atores sociais, imbuídos de uma consciência ética, assumem papel de destaque, preocupando-se em obstar qualquer forma de discriminação e as graves repercussões que dela possam advir, dadas as peculiares condições que a pessoa acometida pela AIDS enfrenta ou que dificultam a adoção de medidas de proteção. A discussão da ética no cenário da AIDS no local de trabalho deve, portanto, priorizar a ética centrada no sujeito, mesmo sabendo que inicialmente haverá descontinuidade entre os comportamentos individuais e coletivos. Afinal a intervenção em resposta ao HIV e a AIDS dependerá não apenas das ações técnicas de saúde pública, mas da capacidade mais ampla em contribuir para promover as transformações sociais, éticas e progressistas de maneira solidária, num ambiente profissional em que as mudanças parecem freqüentemente estar caminhando em direção oposta e em ritmo lento, muito aquém do necessário.

Rorty (1989) considera que a solidariedade, referida anteriormente, está ligada à percepção da diferença, à nossa capacidade de entender e nos identificar com a dor e sofrimento dos outros. Ela extrapola a noção de caridade, ou mesmo, de piedade, muitas vezes, nos ecos e reflexos que cercam a epidemia.

Por fim, a ocorrência da AIDS trouxe-me como enfermeira do trabalho o ensejo impar de buscar o crescimento e desenvolvimento pessoal a partir do instante que reconheci minhas limitações, 
carências e necessidades como ser humano relacional e afetivo frente ao papel de protagonista da minha própria história.

De outra sorte, reafirmo a relevância da participação do profissional enfermeiro como elemento capaz de coordenar o processo de produção das transformações necessárias no modo de pensar e de agir, considerando o respeito à individualidade humana e seus respectivos valores, assim como as possibilidades e os impasses do desenvolvimento evolutivo da qualidade humana, como base para atuação da equipe de saúde ocupacional.

ABSTRACT: The aim of this essay is providing deep reflection regarding the ethical issues which arise from the increasing rise in AIDS cases in the economically active population, mostly in the work environment, putting in evidence the role of the nurse integrated with the health staff and its important contribution in implementing the strategies to prevent and face this disease which cruelly affects human beings.

KEY WORDS: Ethics; nursing; AIDS; workplace.

\section{REFERÊNCIAS}

BRASIL. Ministério da Saúde. Coordenação Nacional de DST/AIDS. Boletim Epidemiológico, Brasília, v.12, 1999.

BRASIL. Ministério da Saúde. Coordenação Nacional de DST/AIDS. Boletim direitos humanos em HIVIAIDS - Cuidando daqueles que cuidam de pessoas vivendo com HIVIAIDS. Brasília, 2000.

BRASIL. Ministério da Saúde. Coordenação Nacional de DST/AIDS. Manual de redução de danos. Brasília, 2001.

BOFF, L. Saber cuidar: ética do humano compaixão pela terra. Petrópolis: Vozes, 1999.

FONTINELE JR., K. Ética e bioética em enfermagem. Goiânia: AB, 2000.

GEIB. L. T. C.; SAUPE, R. Educare: ensaiando a pedagogia do cuidado. Texto\&Contexto,
Florianópolis, v. 9, n. 2, p.497-508, maio/ago, 2000.

GELAIN, I. Deontologia e enfermagem. 3 ed. São Paulo: EPU, 1998.

GOFFMAN, E. Estigma: notas sobre a manipulação de identidade deteriorada. Rio de Janeiro: Guanabara-Koogan, 1988.

LEOPARDI, M. T. Instrumentos de trabalho na saúde: razão e subjetividade. In: Processo de trabalho em saúde: organização e subjetividade. Florianópolis: Programa de Pós Graduação em Enfermagem/UFSC; Papa-Livros,1999.

MANN, J; TARANTOLA, D. J. M; NETTER, T.W. (Org.) A AIDS no mundo. Rio de Janeiro: Relume Dumará/ ABIAI IMS/ UERJ., 1993.

PAIVA, V. (Org.) Em tempos de AIDS: viva a vida: sexo seguro, prevenção, drogas, adolescentes, mulheres, apoio psicológico aos portadores. São Paulo: Summus, 1992.

PARANÁ. Ministério Público. Centro de Apoio Operacional das Promotorias de Defesa dos Direitos e Garantias Constitucionais. Ética e AIDS: pareceres, resoluções e projeto de lei em tramitação. Curitiba: Associação Paranaense do Ministério Público, 1997.

MAIA, C. B. AIDS no local de trabalho. In PARANÁ. Secretaria do Estado da Saúde. Instituto de Saúde do Estado do Paraná. Diretoria de Sistemas em Saúde. Coordenação Estadual de DST e AIDS. Câmara técnica de ética e cidadania em HIV e AIDS. Curitiba: Ministério da Saúde, 2003. Série Caderno 3; Solidariedade.

PEGORARO, O. A. Ética e bioética: da subsistência à existência. Petrópolis: Vozes, 2002.

PESSINI, L; BARCHIFONTAINE, C.,P. Problemas atuais da bioética. 6 ed. São Paulo: Loyola, 2002.

RORTY, R. Contingency, irony, and solidarity. Cambridge: Cambridge University Press, 1989.

SILVA, M. V. Legislação sobre DST\&AIDS no 
Brasil. Brasília: Ministério da Saúde. Coordenação Geral do PN-DST/AIDS, 1995.

VALLE, A. O grupo pela VIDDA. In: LENT, C. F.; VALLE, A. (Org.) Enfrentando o APARTHAIDS. Rio de Janeiro: Banco de Horas - Instituto de Ação Cultural, 1997.

VASQUEZ, A. S. Ética. Rio de Janeiro: Civilização Brasileira, 1999.

VILLELA, W; DINIZ, S. A epidemia da AIDS em mulheres. São Paulo: NEPAIDS/CFSS, 1988.
ZAMPIERI, A. M. F. Sociodrama construtivista da AIDS: método de construção grupal na educação preventiva da síndrome da imunodeficiência adquirida. Campinas: Editorial Psy, 1996.

ENDEREÇODOSAUTORES: R. Major Pedro Abreu Finkenzier, 89 - ap. B3 Novo Mundo - Curitiba / PR Fone: 9969-5126 / 240-5571 carolina.maia@fepar.edu.br 